\title{
S-Antigen and Rod-Opsin Immunoreactions in Midline Brain Neoplasms of Transgenic Mice: Similarities to Pineal Cell Tumors and Certain Medulloblastomas in Man
}

\author{
Horst-W. Korf, M.D., Werner Götz, M.D., RAINER Herken, M.D., \\ Franz Theuring, Ph.D., Peter Gruss, Ph.D., \\ AND WALTER SCHACHENMAYR, M.D.
}

\begin{abstract}
Transgenic mice expressing the large T-antigen of the simian virus 40 (SV 40) under the control of 1) the enhancer of Moloney murine sarcoma virus (MSV) and 2) the SV 40 promoter develop undifferentiated neuroectodermal tumors located in the midline of the dorsal brain surface, abnormalities in lens fiber differentiation and retinal dysplasia. In this study the brain neoplasms of six adult animals and the brain of one 11-day old mouse were examined by conventional histology and immunocytochemical demonstration of S-antigen, rod-opsin, neuron-specific enolase, ncurofilaments ( 160 and $200 \mathrm{kDa}$ ) and glial fibrillary acidic protein. According to histologic criteria the neoplasms were characterized as "primitive" neuroectodermal tumors composed mainly of small cells with scanty and ill-defined cytoplasm. Neoplastic cells displaying immunoreactive $\mathrm{S}$-antigen were found in five brain tumors; three of these tumors also contained a limited number of rod-opsin immunoreactive neoplastic cells. Some tumor cells had neurite-like processes containing immunoreactive neurofilament $(200 \mathrm{kDa})$. No pathologic lesions were found in the brain of the 11-day old animal. Tumors in transgenic mice may resemble pineal cell tumors and a special subtype of medulloblastoma in man. These neoplasms contain S-antigen immunoreactive and also rod-opsin immunoreactive tumors cells in certain cases. The findings suggest that transgenic mice expressing the large T-antigen of SV 40 may become a valuable animal model for analysing the origin, histogenesis and development of primitive neuroectodermal tumors with photoreceptor-like features (pineal cell tumors and certain medulloblastomas).
\end{abstract}

Key Words: Medulloblastoma; Neurofilament; Pineal cell neoplasms; Primitive neuroectodermal tumor; Rod-Opsin; S-antigen; Mice transgenic.

\section{INTRODUCTION}

Transgenic mice are animals that have integrated foreign DNA into their genome as a result of the experimental introduction of DNA $(1,2)$. These animals are now widely used 1) to study the precise temporal and spatial regulation of gene expression during development, mediated by regulatory DNA elements, e.g. enhancers and promoters, and 2) to investigate aspects of tumorigenesis induced by the expression of viral oncogenes (3).

From the Departments of Anatomy and Cytobiology (H-WK) and Neuropathology (WS), Justus Liebig University of Giessen, Giessen, Federal Republic of Germany; the Institute of Anatomy, Department of Histology, University of Göttingen (WG, RH); and the Max-Planck-Institute of Biophysical Chemistry, Department of Molecular Biology, Göttingen, Federal Republic of Germany (FT, PG).

Present address (FT): Schering AG, Berlin, Department of Biochemistry, D-1000 Berlin 65, Federal Republic of Germany.

Correspondence to: Horst-W. Korf, M.D. Department of Anatomy and Cytobiology, Justus Liebig University of Giessen, Aulweg 123, D-6300 Giessen, Federal Republic of Germany.

Supported by grants from the Deutsche Forschungsgemeinschaft to H-WK (Ko 758/3-2). 
One of the first examples of induced tumorigenesis in transgenic animals was found in the brain of mice bearing a fragment of the simian virus 40 (SV 40) genome comprising 1) the early control region which encodes for two viral proteins, large $T$ - and small t- (tumor) antigens, and 2) its own promoter and enhancer $(4,5)$. These animals develop choroid plexus papillomas whose cells express high levels of the $T$-antigen (6). The direct role of the $T$-antigen for oncogenesis was demonstrated by the studies of Brinster et al (7) showing that the expression of the $T$-antigen at the RNA level was high in tumor cells, but low in all somatic tissue prior to the onset of tumorigenesis.

Recently, several independent lines of transgenic mice expressing the large $\mathrm{T}$-antigen of SV 40 under the control of the MSV (Moloney murine sarcoma virus) enhancer and the SV 40 promoter were shown to develop heritable abnormalities in lens fiber differentiation, retinal dysplasia and undifferentiated neuroectodermal tumors located in the midline of the brain and infiltrating the occipital cortex and the cerebellum (8). By location these tumors may correspond to the pineoblastomas (-cytomas) or medulloblastomas of man. This hypothesis was tested in this study which provides results on the histopathologic features and immunocytochemical properties of brain tumors arising in the transgenic mouse lines designated MSV 119, MSV 125 and MSV 126. Particular emphasis was placed on whether tumor cells contain immunoreactive S-antigen and rod-opsin, immunoreactions considered to be highly selective markers for certain medulloblastomas (9-11) and pineal cell tumors (12, 13) in man. The final goal of our studies was to evaluate whether transgenic mice expressing the large $\mathrm{T}$-antigen under control of the MSV enhancer represented an animal model for analysing the origin and histogenesis of primitive neuroectodermal tumors located in the midline of the human brain.

\section{MATERIALS AND METHODS}

\section{Generation of Transgenic Mice}

The complete protocol for generation of transgenic mice has been presented elsewhere (8). In brief, the plasmid MSV-SV40-T was constructed by ligating the EcoRI-SfiI fragment from pMSV CAT, containing the MSV enhancer and the SV 40 promoter with the Sfil-EcoRI fragment encoding for the large T-antigen of SV 40 . The linear DNA fragments were microinjected into the pronucleus of fertilized eggs obtained from hormone primed NMRI females mated with either NMRI or B6D2 males the night before injection. Subsequent to the application of the linear DNA fragment, viable eggs were transferred to the oviducts of hormone primed pseudopregnant NMRI mice. The incorporation of the fragment into the genome was determined by analysing the DNA of cells in the tail with the use of the Southern blot technique (14). Two transgenic males designated as MSV 119 and MSV I 25 transmitted the genetic trait to progeny in a Mendelian fashion. In the line MSV 125, the transgene was integrated into the y-chromosome; the line MSV 119 displayed autosomal integration of the transgene. No line could be established from one sterile transgenic male (MSV 126), which died after 100 days (for further details, see reference 8).

\section{Histology and Immunocytochemistry}

Three males of the line MSV 125, three males of the line MSV 119 and the male MSV 126 were used. One male of the line MSV 125 was killed 11 days after birth by decapitation. The remaining animals of the lines MSV 119 and MSV 125 were decapitated four to eight months after birth when they displayed signs of a rapidly growing brain tumor, i.e. protrusions of the parietal parts of the skull, gait disturbances, ataxia, convulsions and general decline. The male designated as MSV 126 died spontaneously because of a rapidly growing brain tumor.

The brains of the animals were dissected, inspected and fixed in $4 \%$ buffered formalin for 


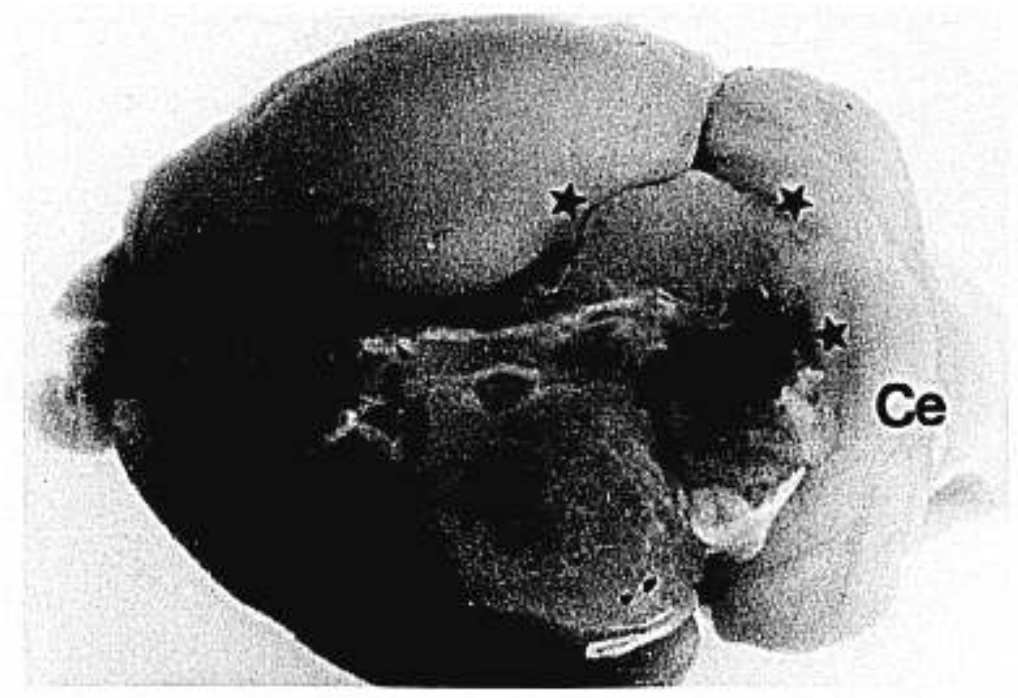

Fig. 1. Dorsal aspect of the brain of a transgenic mouse (MSV 125). $T$, tumor located in the midline; stars mark border of the tumor. Ce, cerebellum; Co, cerebral cortex. $\times 8$.

24-48 hours. They were then embedded in paraffin and cut into serial sections. The sections were stained with hematoxylin and eosin (H\&E) or processed for immunocytochemical demonstration of S-antigen, rod-opsin, neuron-specific enolase (NSE), neurofilaments (NF-M: 160 $\mathrm{kDa}$ and NF-H: $200 \mathrm{kDa}$ ) and glial fibrillary acidic protein (GFAP).

The S-antigen antibody (NEI 04111083 ) was provided by Dr. I. Gery, National Eye Institute, Bethesda, MD, USA. The rod-opsin antibody (CERN-JS 839) was obtained from Dr. W. J. de Grip, Department of Biochemistry, Nijmegen, The Netherlands. The NSE- and GFAPantibodies were purchased from Dakopatts, Copenhagen, Denmark, and the monoclonal antibodies against NF-M and NF-H from Boehringer, Mannheim, FRG. All antibodies have been well characterized by immunocytochemical and immunochemical techniques: rod-opsin antibody (15-17); S-antigen antibody (18-20); NSE- and GFAP-antibodies (see Dakopatts information); NF-M and NF-H (see Boehringer information). The antibodies were used in the following dilutions: S-antigen (1:500); rod-opsin (1:1,600); NSE and GFAP (1:2,000); NF-M and NF-H (1:10). Binding of the polyclonal primary antibodies was visualized by the use of the peroxidase-antiperoxidase technique (21) according to a protocol previously described in detail $(17,18)$. Binding of the monoclonal antibodies against NF-M and NF-H was visualized by use of peroxidase-labeled rabbit anti-mouse antibodies (Dakopatts).

\section{RESULTS \\ Macroscopic Findings}

The brain of the 11.day old male of the line MSV 125 appeared normal. The brains of all remaining animals (MSV 125, MSV 126, MSV 119; four to eight months old) contained a midline tumor displacing considerable portions of the occipital and parietal cortex and the cerebellum. The pineal organ seemed to be destroyed by the infiltrating tumor in all cases (Fig. 1).

\section{Histology}

Sections stained with $H$ \& $E$ revealed no signs of neoplastic tissue or cells in the brain of the 11-day old animal of the line MSV 125. As is typical of individuals at this age, the fetal granular layer of the cerebellum could be clearly distinguished; it did not display any pathologic features (Fig. 2a, b). 

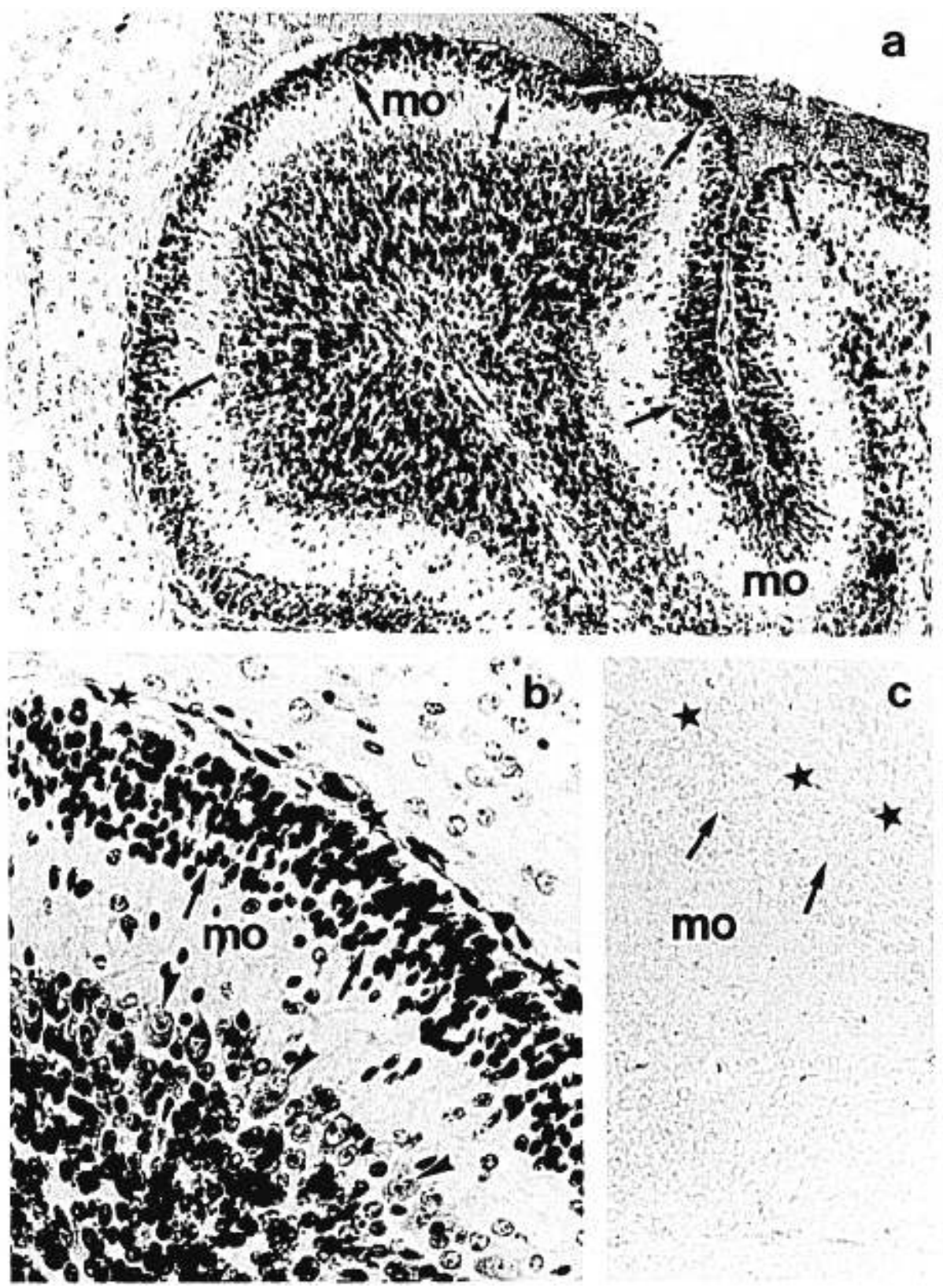

Fig. 2. Cerebral cortex and cerebellum of an 11-day old transgenic mouse (MSV 119). a, b: Fetal granular layer (arrows) of the cerebellum appears normal. mo, molecular layer; arrowheads, Purkinje cells; stars, leptomeninges. H\&E. a: $\times 140 ;$ b: $\times 330$. c: Immunocytochemistry for S-antigen. Fetal granular layer (arrows) and all other elements of the cerebellum are devoid of S-antigen immunoreaction. mo, molecular layer; stars, leptomeninges. $\times 330$.

The tumors found in adult mice were highly cellular neoplasms (Figs. 3a-c, 4ac). Most cells were small and undifferentiated and contained round to oval nuclei which were often hyperchromatic. The cytoplasm of these cells was scanty and illdefined. The small tumor cells occasionally formed rosettes (Fig. 4a). In addition, 

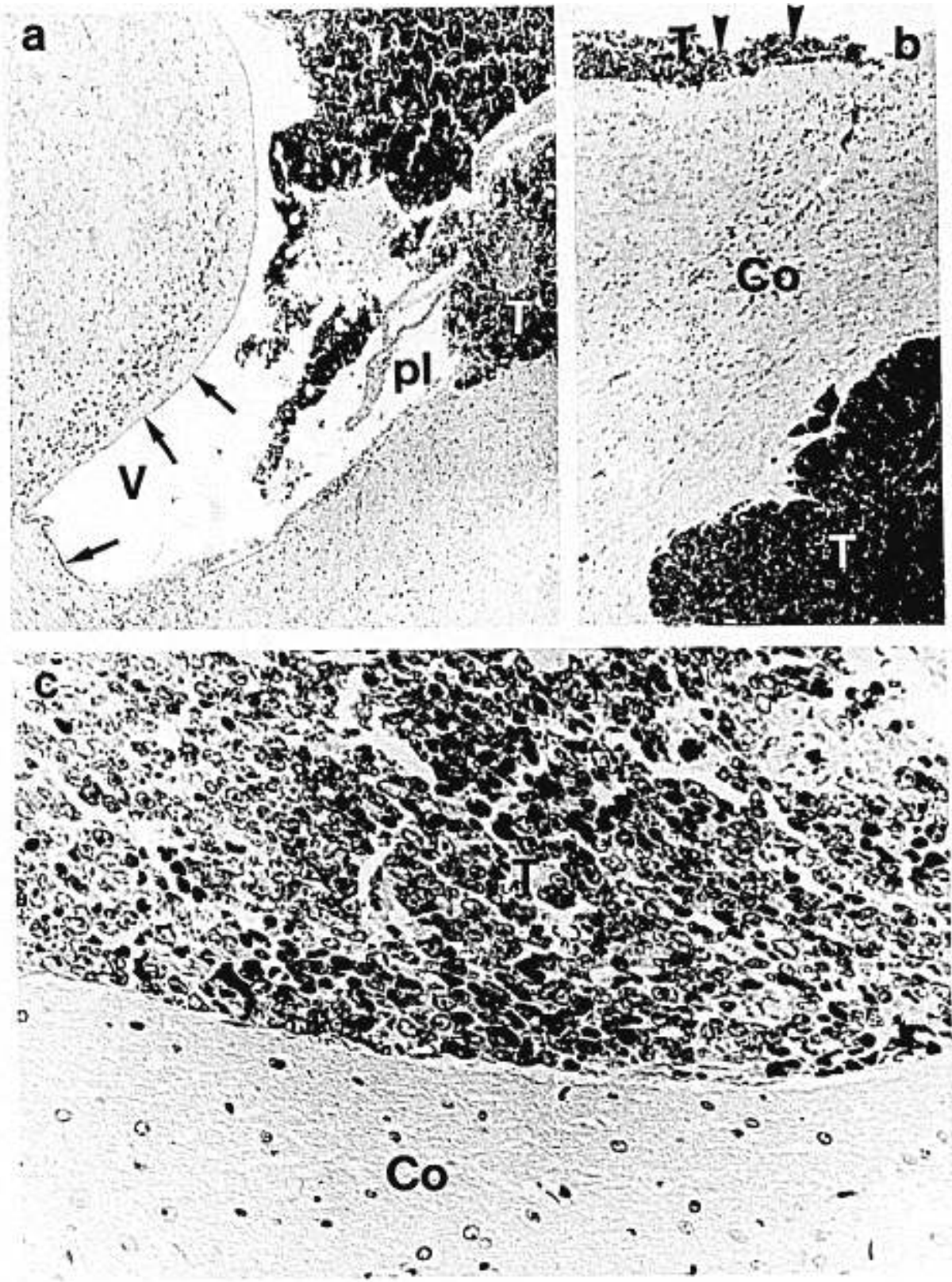

Fig. 3. Brain tumors in transgenic mice (MSV 119). a: The tumor (T) spreads along the lateral ventricle (V). Arrows, ependyma; pl, choroid plexus. H\&E. $\times 60$. b: The tumor $(T)$ spreads along the subarachnoid space (arrowheads). Co, cerebral cortex. H\&E. $\times 60 . \mathrm{c:}$ Tumor $(\mathrm{T})$ in the subarachnoid space does not invade the cortex (Co). H\&E. $\times 400$.

medium-sized tumor cells occurred in circumscribed regions (Fig. 4a, b). The number of the medium-sized elements varied considerably among individual animals and also from region to region within a tumor. Their nuclei were less dense than those of the small tumor cells and they could contain two or more prominent nucleoli. Single giant cells were scattered between the small and medium-sized tumor cells 

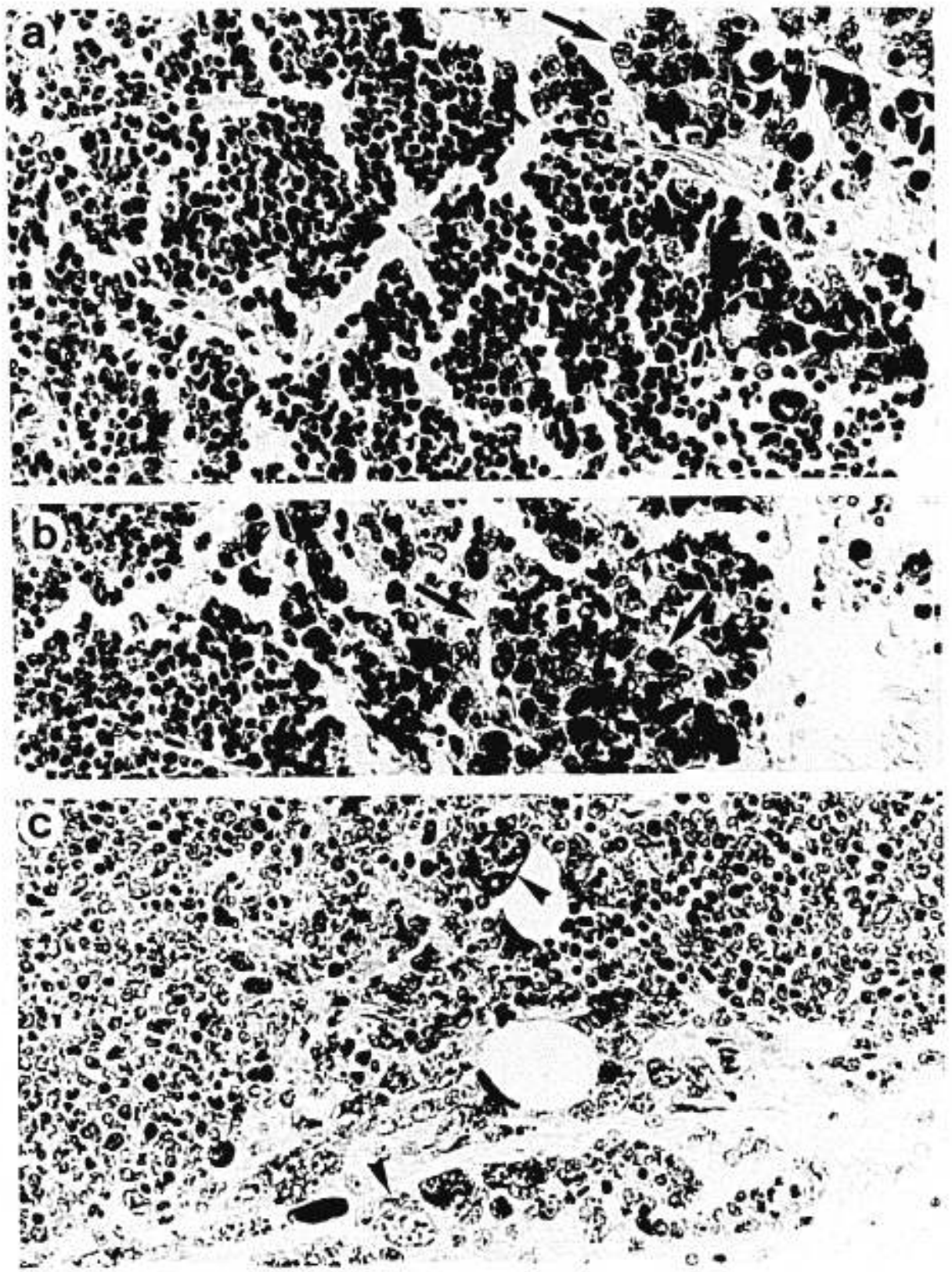

Fig. 4. Cytological details of brain tumors in transgenic mice (MSV 119, MSV 125). a, b: MSV 125. Smail cells with hyperchromatic nuclei and ill-defined cytoplasm form most of the tumors. These cells, occasionally arranged in rosettes, are intermingled with groups of mediumsized cells (arrows). c: MSV 119. Giant cells (arrowheads) are occasionally found in the tumors. a-c: H\&E. $\times 400$.

(Fig. 4c). Necroses of single or multiple cells, karyopyknoses and mitoses were occasionally seen.

The neoplasm infiltrated brain tissue (Fig. 3a-c) and in general, the infiltrations were sharply demarcated. Often the tumor spread along the ventricular system (Fig. 3a) or the subarachnoid space (Fig. $3 b, c$ ). 

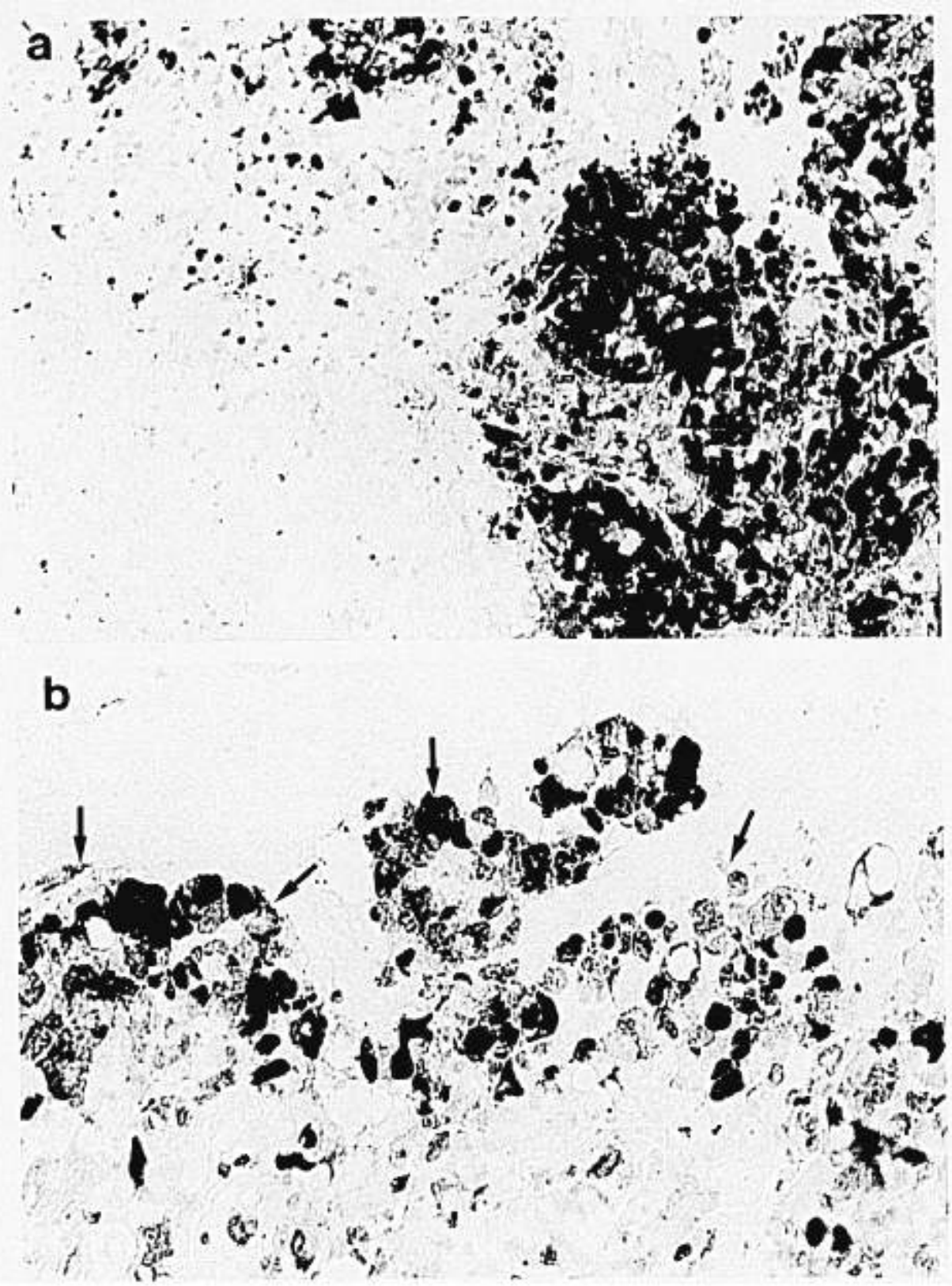

Fig. 5. Immunocytochemical demonstration of S-antigen in brain tumors of transgenic mice (MSV 119). a: The immunoreaction is localized to medium-sized and small tumor cells. The intensity of the immunoreaction shows considerable cell-to-cell variation. Nuclei are devoid of immunoreaction. $\times 140$. b: Border between tumor and normal brain tissue (arrows). Several of the infiltrating tumor cells are S-antigen-immunoreactive. $\times 380$.

\section{Immunocytochemistry}

Immunoreactive S-antigen was found in five brain tumors (Figs. 5, 6). One neoplasm lacked S-antigen immunoreaction. The marker was also absent from the fetal granular layer of the cerebellum of the 11-day old mouse (Fig. 2c). 


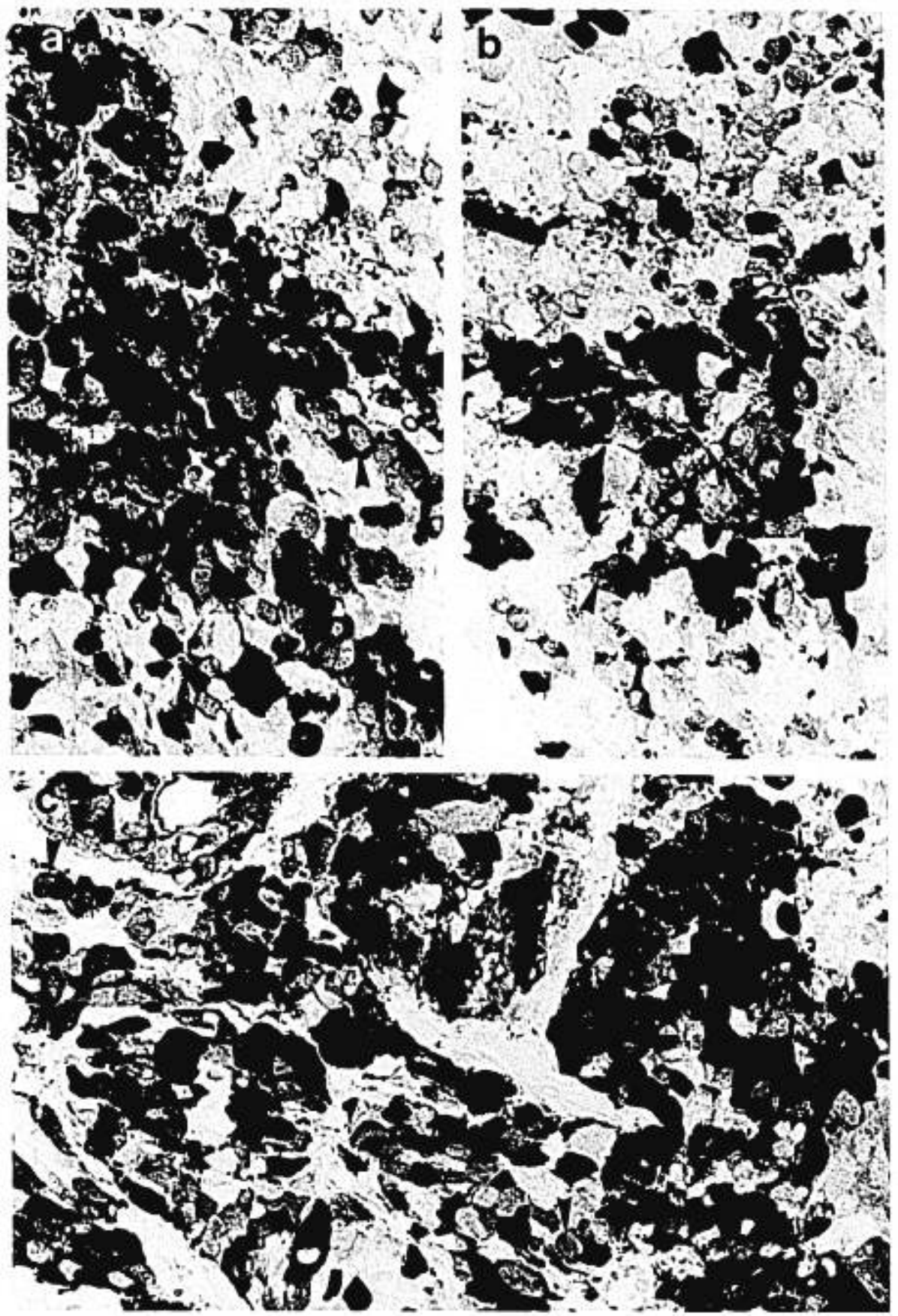

Fig, 6. Immunocytochemical demonstration of S-antigen in brain tumors of transgenic mice (MSV 125). a-c: The distribution pattern and intensity of the immunoreaction are similar to those demonstrated in the tumors of the transgenic mice MSV 119 (compare with Fig. 5). Nuclei (arrowheads) are devoid of immunoreaction. a-c: $\times 600$. 


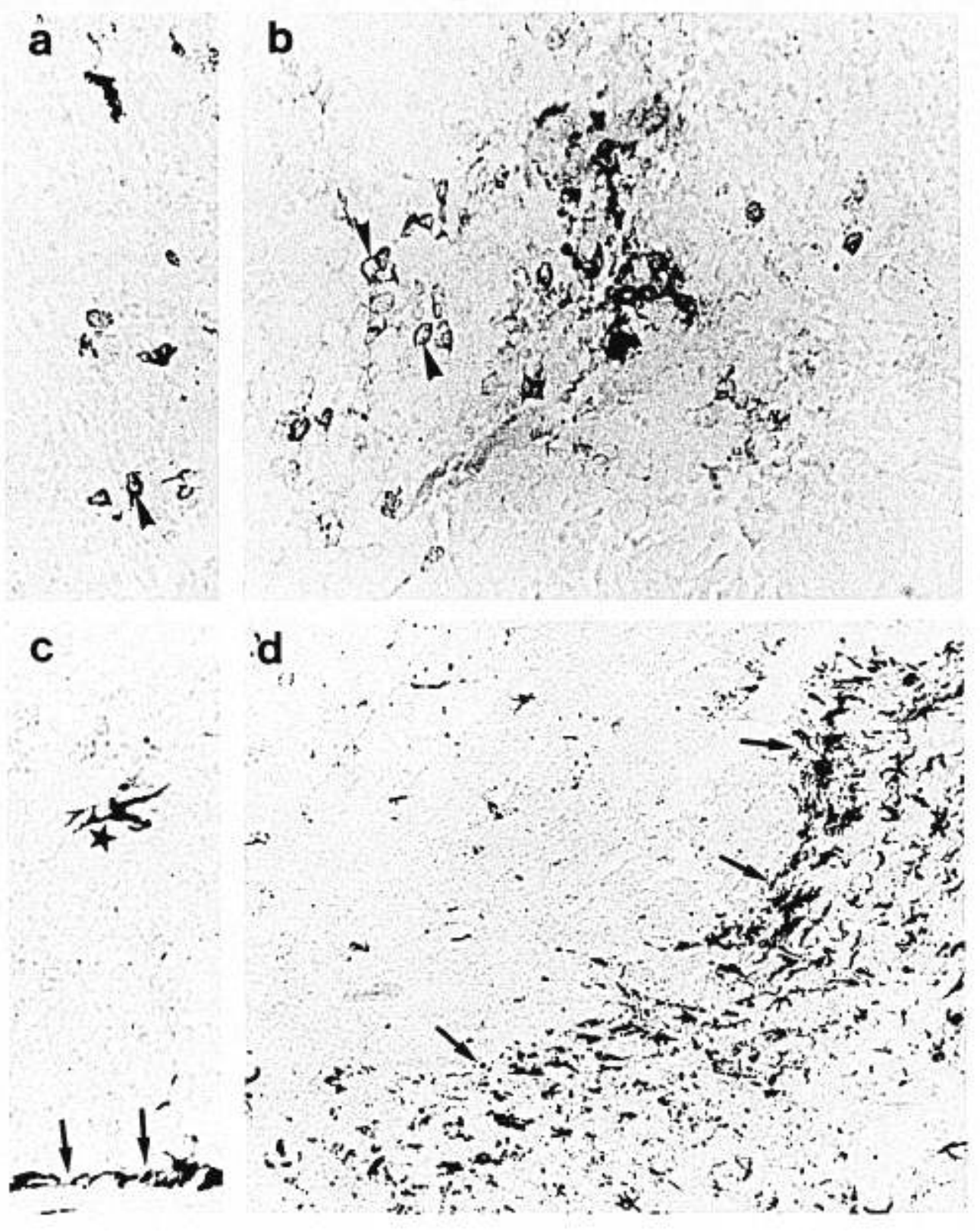

Fig. 7. Immunocytochemical demonstration of rod-opsin and GFAP in brain tumors of transgenic mice (MSV 125). a, b: Rod-opsin-immunoreactive cells are less frequent than S-antigen immunoreactive ones. The immunoreaction is prominent in the region of the cell membrane (arrowheads). $\times 330 . \mathrm{c}, \mathrm{d}:$ Astrocytes and glial fibers demarcating the tumor (arrows) display strong GFAP-immunoreaction. Single astrocytes of normal appearance (star) and scattered glial fibers are found within the tumor masses. $\mathrm{c}: \times 330 ; \mathrm{d}: \times 140$.

In the positive cases, the S-antigen immunoreaction was confined to the perikarya of certain tumor cells whose number varied considerably among the five tumors. The S-antigen immunoreaction predominantly occurred in the medium-sized tumor cells (Figs. 5a, b, 6a-c), but was also found in some small neoplastic elements (Fig. 

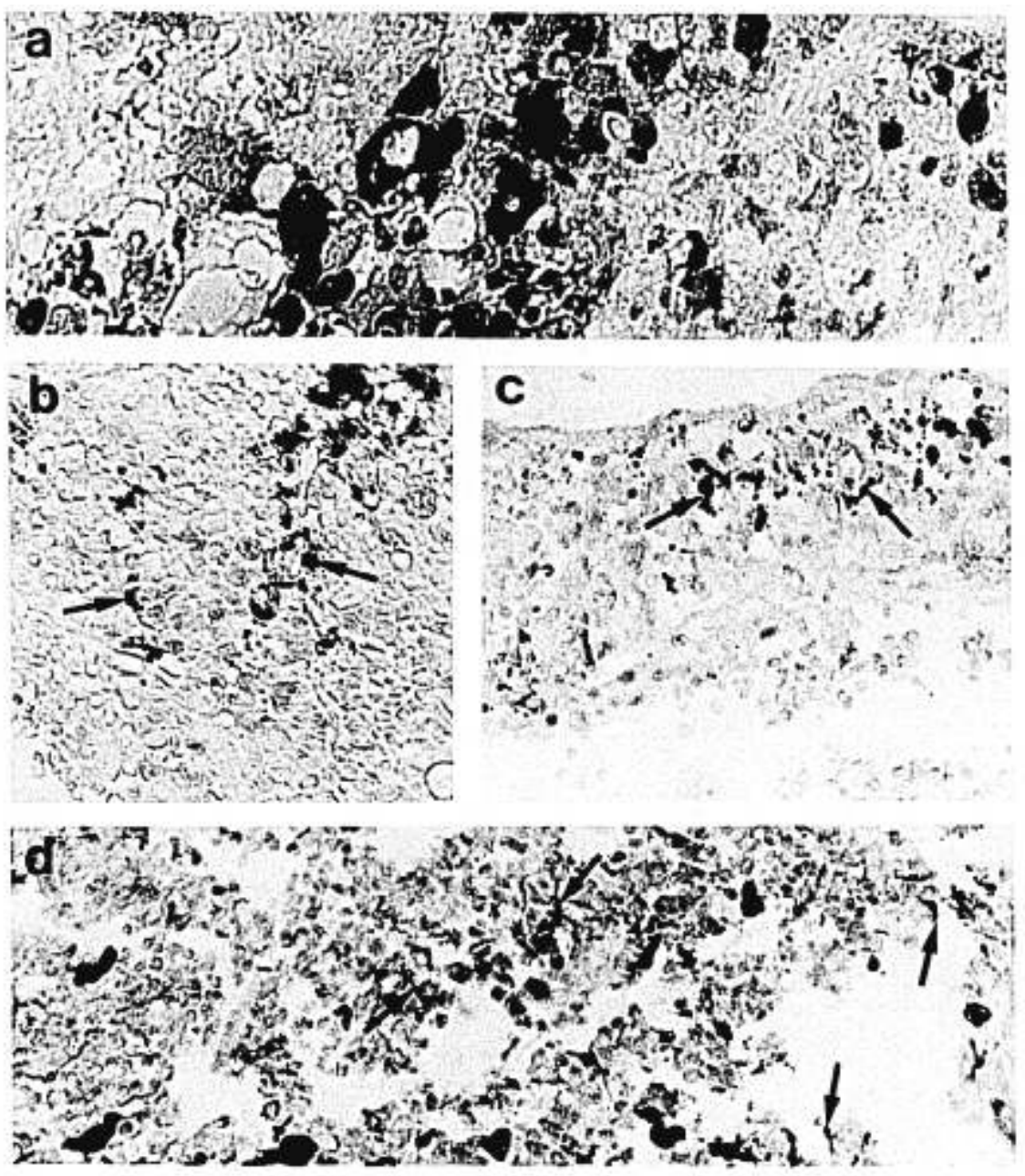

Fig. 8. Immunocytochemical demonstration of neuronal markers in brain tumors of transgenic mice (MSV 119, MSV 125), a: MSV 119. Several small and medium-sized tumor cells display NSE-immunoreactivity. $\times 380$. b-d: MSV 125 . NF-H-immunoreactive profiles (arrows) are found in circumscribed tumor regions. $\times 330$.

5a). Strongly immunoreactive cells could be distinguished from weakly labeled ones (Fig. 6a-c).

Immunoreactive rod-opsin was found in three brain tumors (Fig. 7a, b); it was absent from the remaining three neoplasms and also from the fetal granular layer of the cerebellum. In the positive cases, the rod-opsin immunoreaction was restricted to very few cells whose number was consistently smaller than that of the S-antigen immunoreactive cells. The rod-opsin immunoreaction appeared more intense in the periphery of the cells (Fig. 7a, b). Occasionally, immunolabeled processes were observed.

Immunoreactive GFAP mainly occurred in astrocytes located in normal brain tissue. At the border between normal parenchyma of the brain and tumor tissue, the astrocytes were strongly immunoreactive and gave rise to several processes (Fig. 7c, d). Rarely, immunoreactive astrocytes and glial fibers were located within the 
tumor masses (Fig. 7c, d). The tumor cells themselves were free of GFAP-immunoreaction.

A varying number of tumor cells was immunoreactive for neuron-specific enolase (Fig. 8a). Immunoreactive NF-H was confined to dotlike structures probably corresponding to neurites of the tumor cells (Fig. $8 \mathrm{~b}-\mathrm{d}$ ). These profiles were restricted to a few circumscribed regions of the tumors. NF-M immunoreactions were never observed in the tumor material, although numerous neurites and scattered neuronal perikarya of the brain were NF-M immunoreactive.

\section{DISCUSSION}

Recently Theuring et al (8) succeeded in generating transgenic mice expressing the large T-antigen of the SV 40 under the control of the MSV enhancer and the SV 40 promoter. These transgenic mice develop heritable abnormalities in lens fiber differentiation, retinal dysplasia and tumors located in the midline of the brain. The brain tumors become obvious in adult animals. Previous studies have established that the expression of the large $\mathrm{T}$-antigen is an essential step in tumorigenesis induced by viral oncogenes (4). In accord with this concept, several cells of the midline brain tumors were shown to contain large T-antigen immunoreactivity (8). In this study, attempts were made 1) to characterize the brain tumors in the midline of the transgenic mice by means of neurohistopathology and immunocytochemistry and, 2) to compare their microscopic appearance and immunocytochemical features with tumors arising in man.

Histologic examination revealed that the brain tumors were identical in all lines of mice investigated (MSV 119, 125 and 126). The neoplasms were comprised of numerous small cells with scanty and ill-defined cytoplasm and a high nuclear-tocytoplasmic ratio. Medium-sized tumor cells and, rarely, giant cells were intermingled between the small tumor cells. Subarachnoid and ventricular dissemination was found in most cases. The poorly differentiated neoplasms were very similar to certain tumors arising in laboratory animals after infection with SV 40 , BK or JC viruses (22-24).

Whether the midline brain tumors in transgenic mice may be compared with primitive neuroectodermal tumors arising in the midline of the human brain (25) is of paramount importance. As has been shown in three rodent species (mouse, hamster, rat) by Ogawa (26), intracranial inoculation with human adenovirus type 12 induced tumors which developed at several sites in the brain and spinal cord and which may have no exact equivalent in man. Consequently, species differences must be considered when evaluating the significance of experimental tumor models for tumorigenesis in man. Parallels between tumors in animals and man can be most appropriately established by immunocytochemical and molecular analysis. Therefore, we characterized the midline brain tumors induced in transgenic mice by immunocytochemical demonstration of S-antigen, rod-opsin and glial fibrillary acidic protein (GFAP), neuron-specific enolase (NSE) and two neurofilaments (NF-M, NF-H).

In the non-neoplastic state, S-antigen and rod-opsin are exclusively found in retinal photoreceptors and a class of pinealocytes derived from pineal photoreceptors of poikilothermic vertebrates (27). Immunoreactive rod-opsin or S-antigen also occur in three distinct types of primitive neuroectodermal tumors of man: retinoblastoma $(28,29)$; pineal cell tumors such as pineocytoma and pineoblastoma $(12,13)$, and a certain subtype of medullobiastoma (9-11). The two molecules appear to be highly selective markers for these neoplasms, since they have not been detected in 
any other type of neuroectodermal tumor investigated to date, e.g. ganglioneuroblastoma, neuroblastoma, ganglioglioma, glioblastoma (9).

The immunocytochemical demonstration of rod-opsin or S-antigen in brain tumors of all three types of transgenic mice (MSV 119, 125 and 126) suggests that these neoplasms are comparable to human pineal cell tumors and the subtype of medulloblastoma displaying photoreceptor-like features. The patterns of GFAPimmunoreactivity of the tumors in mice are also very similar to those in pineocytomas, pineoblastomas, retinoblastomas or medulloblastomas of man. In all tumors, the GFAP immunoreaction was mainly found in well-differentiated glial cells that were interpreted as being reactive and not neoplastic $(30,31)$. The focal distribution of NSE and NF-H also resembles the pattern found in human medulloblastomas $(31,32)$.

Additional parallels between the tumors induced in transgenic mice and human pineal cell tumors and medulloblastomas may also be revealed in future electron microscopic studies. The ultrastructural investigations should be focussed on a search for dense-core vesicles and vesicle-crowned rodlets (synaptic ribbons). These features, highly characteristic of normal mammalian pinealocytes (33), were found in the experimental pineocytoma induced in hamster by the JC human polyoma virus (23), in human parenchymal tumors (34) and in human medulloblastoma cells cultured for several months (35).

The immunocytochemical results presented in this paper clearly suggest that transgenic mice MSV 119 and MSV 125 are an interesting animal model for the study of the origin, histogenesis and development of primitive neuroectodermal tumors with photoreceptor-like differentiation. Such investigations may contribute information for resolving the fundamental problem 1) whether the stem cell of these tumors is unique to that portion of the brain in which the tumor arises, or 2) whether the tumors originate from a single primitive neuroepithelial cell common to all portions of the nervous system and endowed with the capacity to differentiate into one or more cell lines, e.g. neuronal and glial, or 3) whether the undifferentiated tumor cell results from the neoplastic transformation of a previously differentiated element (25).

Currently, we address these problems by investigating animals of MSV 125 at different developmental stages. Special attention is paid to the pineal organ shown to be destroyed by the midline brain tumors and the fetal granular layer in the cerebellum assumed to be a matrix for certain medulloblastomas (36). Preliminary findings suggest that the tumors in transgenic mice develop from the pineal parenchyma which, at a certain point of development, begins to express the large T-antigen (Götz, Korf, Herken, Theuring, Gruss and Schachenmayr, unpublished results). In accordance with the present study, the granular layer of the cerebellum appears unaffected. If confirmed, these data would indicate that at least certain cells of "primitive" neuroectodermal tumors retain the immunocytochemical features characteristic of the parent tissue. Our results also raise the interesting question of which tissue-specific mechanisms may account for the highly selective expression of the transgene within the pineal parenchyma.

\section{ACKNOWLEDGMENTS}

We thank Dr. R. L. Snipes, Giessen, for Iinguistic advice and Ms. I. Habazettl for skillful technical assistance. Polyclonal antisera against S-antigen and rod-opsin were generous gifts from Dr. I Gery, National Eye Institute, Bethesda, MD, USA, and Dr. W. de Grip, Department of Biochemistry, Nijmegen, The Netherlands. 


\section{REFERENCES}

1. Gordon JW, Ruddle FH. Gene transfer into mouse embryos: Production of transgenic mice by pronuclear injection. Methods Enzymol 1983;101:411-33

2. Palmiter RD, Brinster RL. Germ line transformation of mice. In: Campbell A, Herskowitz I, Sandler LM, eds. Annual review of genetics. Volume 20, 1986. Palo Alto: Annual Reviews, 1986:465-99

3. Gordon JW. Transgenic animals. In: Bourne GH, Jeon KW, Friedlander M, eds. International review of cytology. A survey of cell biology. Volume 115. San Diego: Academic Press, 1989:171-229

4. Palmiter RD, Chen HY, Messing A, Brinster RL. SV 40 enhancer and large T-antigen are instrumental in development of choroid plexus tumours in transgenic mice. (Letter) Nature 1985;316:457-60

5. Small JA, Blair DG, Showalter SD, Scangos GA. Analysis of a transgenic mouse containing simian virus 40 and $v$-myc sequences. Mol Cell Biol 1985;5:642-8

6. Van Dyke TA, Finlay C, Miller D, Marks J, Lozano $G$, Levine AJ. Relationships between simian virus 40 large tumor antigen expression and tumor formation in transgenic mice. J Virol 1987;61: 2029-32

7. Brinster RL, Chen HY, Messing A, van Dyke T, Levine AJ, Paimiter RD. Transgenic mice harboring SV 40 T-antigen genes develop characteristic brain tumors. Cell 1984;37:367-79

8. Theuring F, Götz W, Balling R, Korl H-W, Schulze F, Herken R, Gruss P. Tumorigenesis and eye abnormalities in transgenic mice expressing MSV-SV 40 large T-antigen. Oncogene 1990;5:225-32

9. Korf H-W, Czerwionka M, Reiner J, et al, Immunocytochemical evidence of molecular photoreceptor markers in cerebellar medulloblastomas. Cancer 1987;60:1763-6

10. Bonnin JM, Perentes E. Retinal S-antigen immunorcactivity in medulloblastomas. Acta Neuropathol (Berl) 1988;76:204-7

11. Czerwionka M, Korf $\mathrm{H}-\mathrm{W}$, Hoffman $\mathrm{O}$, Busch $\mathrm{H}$, Schachenmayr W. Differentiation in medulloblastomas: Correlation between the immunocylochemical demonstration of photoreceptor markers (S-antigen, rod-opsin) and the survival rate in 66 patients. Acta Neuropathol (Berl) 1989;78:629-36

12. Korf H-W, Klein DC, Zigler JS, Gery I, Schachenmayr W. S-antigen-like immunoreactivity in a human pineocytoma. Acta Neuropathol (Berl) 1986;69:165-7

13. Perentes $E$, Rubinstein LJ, Herman MM, Donoso LA. S-antigen immunoreactivity in human pineal glands and pineal parenchymal tumors. A monoclonal antibody study. Acta Neuropathol (Berl) 1986; 71:224-7

14. Southern EM. Detection of specific sequences among DNA fragments separated by gel electrophoresis. J Mol Biol 1975;98:503-17

15. Schalken JJ, de Grip WJ. Enzyme-linked immunosorbent assay for quantitative determination of the visual pigment rhodopsin in total-eye extracts. Exp Eye Res 1986;43:431-9

16. Schalken JJ, Janssen JJM, de Grip WJ, Hawkins RK, Sanyal S. Immunoassay of rod visual pigment (opsin) in the eyes of $r d s$ mutant mice lacking receptor outer segments. Biochim Biophys Acta 1985; $839: 122-6$

17. Korf H-W, Foster RG, Ekström P, Schalken JJ. Opsin-like immunoreaction in the retinae and pineal organs of fous mammalian species. Cell Tissue Res 1985;242:645-8

18. Korr H-W, Møller M, Gery I, Zigler JS, Klein DC. Immunocytochemical demonstration of retinal S-antigen in the pineal organ of four mammalian species. Cell Tissue Res 1985;239:81-5

19. van Veen T, Elofsson R, Hartwig H-G, Gery I, Mochizuki M, Klein DC. Retinal S-antigen: Immunocytochemical and immunochemical studies on distribution in animal photoreceptors and pineal organs, Exp Biol 1986;45:15-25

20. Müller B, Peichl L, de Grip WJ, Gery I, Korf H-W. Opsin- and S-antigen-like immunoreactions in photoreceptors of the tree shrew retina. Invest Ophthalmol Vis Sci 1989;30:530-5

21. Sternberger LA, Hardy PH Jr, Cuculis JJ, Meyer HG. The unlabeled antibody enzyme method of immunohistochemistry. Preparation and properties of soluble antigen-antibody complex (horseradish peroxidase-antihorseradish peroxidase) and its use in identification of spirochetes. J Histochem Cylochem 1970;18:315-33

22. Varakis $J N_{1}$ zu Rhein GM. Experimental pineocytoma of the Syrian hamster induced by human papovavirus (JC). A light and electron microscopic study. Acta Neuropathol (Berl) 1976;35:243-64

23. zu Rhein GM, Varakis JN. Perinatal induction of medulloblastomas in Syrian golden hamster by a human polyoma virus (JC). In: Rice JM, ed. Perinatal carcinogenesis. National Cancer Institute Monograph 51. Bethesda: US Department of Health, Education, and Welfare, 1979:205-8

24. Walsh JW, Zimmer SG, Perdue ML. Role of viruses in the induction of primary intracranial tumors. Neurosurgery 1982; 10:643-62

25. Rorke LB, Gilles FH, Davis RL, Becker LE. Revision of the World Health Organization classification of brain tumors for childhood brain tumors. Cancer 1985;56:1869 86 
26. Ogawa K. Embryonal neuroepithelial tumors induced by human adenovirus type 12 in rodents. 2. 'rumor induction in the central nervous system. Acta Neuropathol (Berl) 1989;78:232-44

27. Korf $\mathbf{H}-$ W, Ekström P. Photoreceptor differentiation and neuronal organization of the pineal organ. In: Trentini GP, De Gaetani C, Pévet P, eds. Fundamentals and clinics in pineal research. New York: Raven Press, 1987:35-47

28. Donoso LA, Felberg NT, Augsburger JJ, Shields JA. Retinal S-antigen and retinoblastoma: A monoclonal antibody and flow cytometric study. Invest Ophthalmol Vis Sci 1985;26:568-71

29. Donoso LA, Hamm H, Dictzschold B, Augsburger JJ, Shield JA, Arbizo V. Rhodopsin and retinoblastoma. A monoclonal antibody histopathologic study. Arch Ophthalmol 1986;109:111-3

30. Perenies E, Herbort CP, Rubinstein $\mathrm{LJ}$, et al. Immunohistochemical characterization of human retinoblastomas in situ with multiple markers. Am J Ophthalmol 1987;103:647-58

31. Burger PC, Grahmann FC, Bliestle A, Kleihues P. Differentiation in the medulloblastoma. A histological and immunohistochemical study. Acta Neuropathol (Berl) 1987;73:115-23

32. Schwechheimer K, Wiedenmann B, Franke WW. Synaptophysin: A reliable marker for medulloblastomas. Virchows Arch A 1987;411:53-9

33. Vollrath L. The pineal organ. In: Oksche A, Vollrath L, eds. Handbuch der Mikroskopischen Anatomie des Menschen. Volume V1/7. Berlin: Springer, 1981:1-665

34. Hassoun J, Gambarelli D, Peragut JC, Toga M. Specific ulirastructural markers of human pinealomas. Acla Neuropathol (Berl) 1983;62:31-40

35. Herman MM, Rubinstein LJ. Divergent glial and neuronal differentiation in a cerebellar medulloblastoma in an organ culture sys1em: In vitro occurrence of symaptic ribbons. Acta Neuropathol (Berl) 1984;65:10-24

36. Russell DS, Rubinstein LJ. Pathology of tumours of the nervous system. 5th Edition. London: Edward Arnold, 1989

(Received July 25, 1989/Accepted October 30, 1989)

MS89-56 